\title{
Samband mellan alkohol och självmord på befolkningsnivå: en översikt
}

Ved Thor Norström

\begin{abstract}
Alltsedan Durkheims klassiska arbete (Durkheim 1952 [1897]) har självmordstalets samband med olika sociala faktorer varit ett vitalt forskningsområde inom samhällsvetenskap. Inom denna tradition var dock alkoholfaktorn länge negligerad som en tänkbar orsak bakom

självmord.
\end{abstract}

\begin{abstract}
I sitt inflytelserika arbete avfärdade Durkheim kategoriskt alkoholkonsumtion eller alkoholmissbruk som en plausibel orsaksfaktor bakom självmord. Detta kan vara ett skäl till att alkoholfaktorn länge var negligerad inom den samhällsvetenskapliga självmordsforskningen. Under de senaste decennierna har dock det publicerats ett växande antal studier på befolkningsnivå där frågeställningen gäller hur förändringar i totalkonsumtionen av alkohol påverkar självmordsfrekvensen i samhället. Föreliggande artikel ger en översikt över den forskning som publicerats på detta område efter 1989. Genom sökningar i MedLine och Social Sciences Citation Index kompletterade med manuella sökningar identifierades 42 relevanta studier. De flesta (34) av de 42 studierna presenterar genusspecifika estimat av sambandet mellan totalkonsumtionen av alkohol och självmord. Av dessa var $53 \%$ signifikant positiva för män, motsvarande siffra för kvinnor var $37 \%$. Ingen studie rapporterade ett signifikant negativt samband. Det finns en tydlig kulturell variation i sambandets styrka; det tenderar att vara starkare ju mer landets dryckesmönster är inriktat mot berusningsdrickande. Det konkluderas att studierna utgör en breddning av såväl självmordsforskning (genom att inkludera alkoholfaktorn) som alkoholepidemiologisk forskning (genom att bredda utfallspanoramat från somatiska till sociala skador). De flesta studier baseras dock på data från utvecklade västländer. Framtida studier bör vidgas till ett bredare urval av länder.
\end{abstract}

In his influential work Durkheim rejected drinking as a plausible causal factor for suicide. This may be one reason why the alcohol factor was long neglected in sociological suicide research. However, recent decades have witnessed a growing number of studies on the population level where the issue is how changes in alcohol consumption affect the suicide rate. The present article provides an overview of the research published in this area after 1989. Through searches of MedLine and Social Sciences Citation Index supplemented by manual searches 42 relevant studies were identified. Most (34) of the 42 studies present gender-specific estimates of the relationship between alcohol consumption and suicide. Of these, $53 \%$ were significantly positive for males, and $37 \%$ for females. No study reported a significant negative relationship. There is a distinct cultural variation in the strength of the relationship: it tends to be stronger the more the country's drinking patterns are geared towards binge drinking. It is concluded that the studies represent a broadening of the suicide research (by including the alcohol factor) as well as alcohol epidemiological research (by broadening the outcome panorama from somatic to social harm). However, most studies are based on data from developed Western countries. Future studies should include a broader range of countries.
I Stacks översiktsartikel från 1982 (Stack 1982) som täcker alla artiklar om självmord som publicerades i Sociological Abstracts (N>200) mellan 1970 och 1980 nämns inte ordet alkohol. En sökning $i$ Social Sciences Citation Index ger vid handen att av de 257 artiklar om självmord som publicerades inom kategorin sociologi under perioden 1960-1989, nämndes alkohol bara i en artikel (0,3 \%). Under de senaste decennierna har dock alkoholfaktorn fått ökad uppmärksamhet inom sociologisk självmordsforskning. Ett tecken på detta är att Stacks senaste översikt (Stack 2000) innehåller ett särskilt avsnitt som behandlar kopplingen mellan alkohol och självmord. Vidare, en sökning enligt samma kriterier som ovan i Social Sciences Citation Index men för perioden 1990-2013 visar att 32 av 401 självmordsartiklar (8 \%) nämner alkohol.

En typ av studier på detta område som ökat starkt under de senaste decennierna är analyser på befolkningsnivå där frågeställningen gäller hur förändringar i totalkonsumtionen av alkohol påverkar självmordsfrekvensen i samhället. Flera av dessa studier genomfördes inom ramen för International Project on Alcohol and Suicide (IPAS). Detta var ett nätverk av forskare från nära tio länder som bildades på initiativ av Ole-Jørgen Skog inom ramen för Kettil Bruun Society i början av 1990talet.

Föreliggande artikel ger en översikt över den samhällsvetenskapliga och socialepidemiologiska forskningen efter 1989 om sambandet mellan alkohol och självmord på befolkningsnivå. Som en inledning beskriver jag först tänkbara mekanismer bakom kopplingen mellan alkohol och självmord, vidare behandlar jag kortfattat de metodologiska komplikationer man möter vid aggregerade analyser av det aktuella sambandet.

\section{Mekanismer bakom kopplingen mellan alkohol och självmord}

En trolig förklaring till att alkoholfaktorn haft en så undanskymd plats inom sociologisk suicidforskning är att Durkheim i sitt inflytelserika arbete kategoriskt avfärdade alkoholkonsumtion eller alkoholmissbruk som en plausibel orsaksfaktor bakom självmord. Durkheim betraktade alkoholfaktorn främst i termer av alkoholism, som han såg som en patologisk individnivåfaktor utan socio-kulturell förankring, vilken kunde ha betydelse i enskilda fall, men som saknade förklaringsvärde för det som Durkheim fokuserade på, variationer i det sociala självmordstalet mellan befolkningsgrupper och över tid och rum.

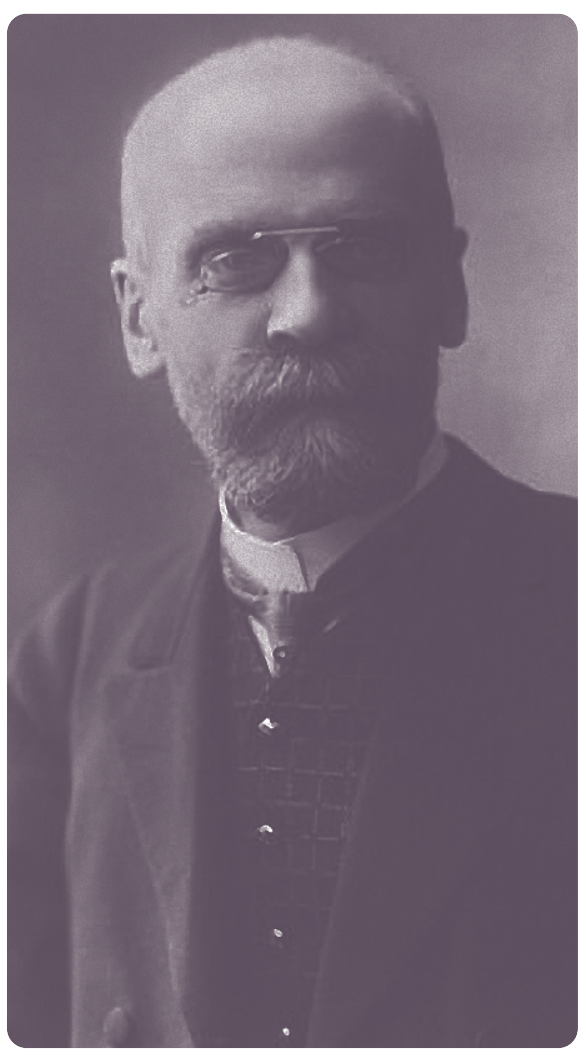

David Émile Durkheim (1858-1917) 


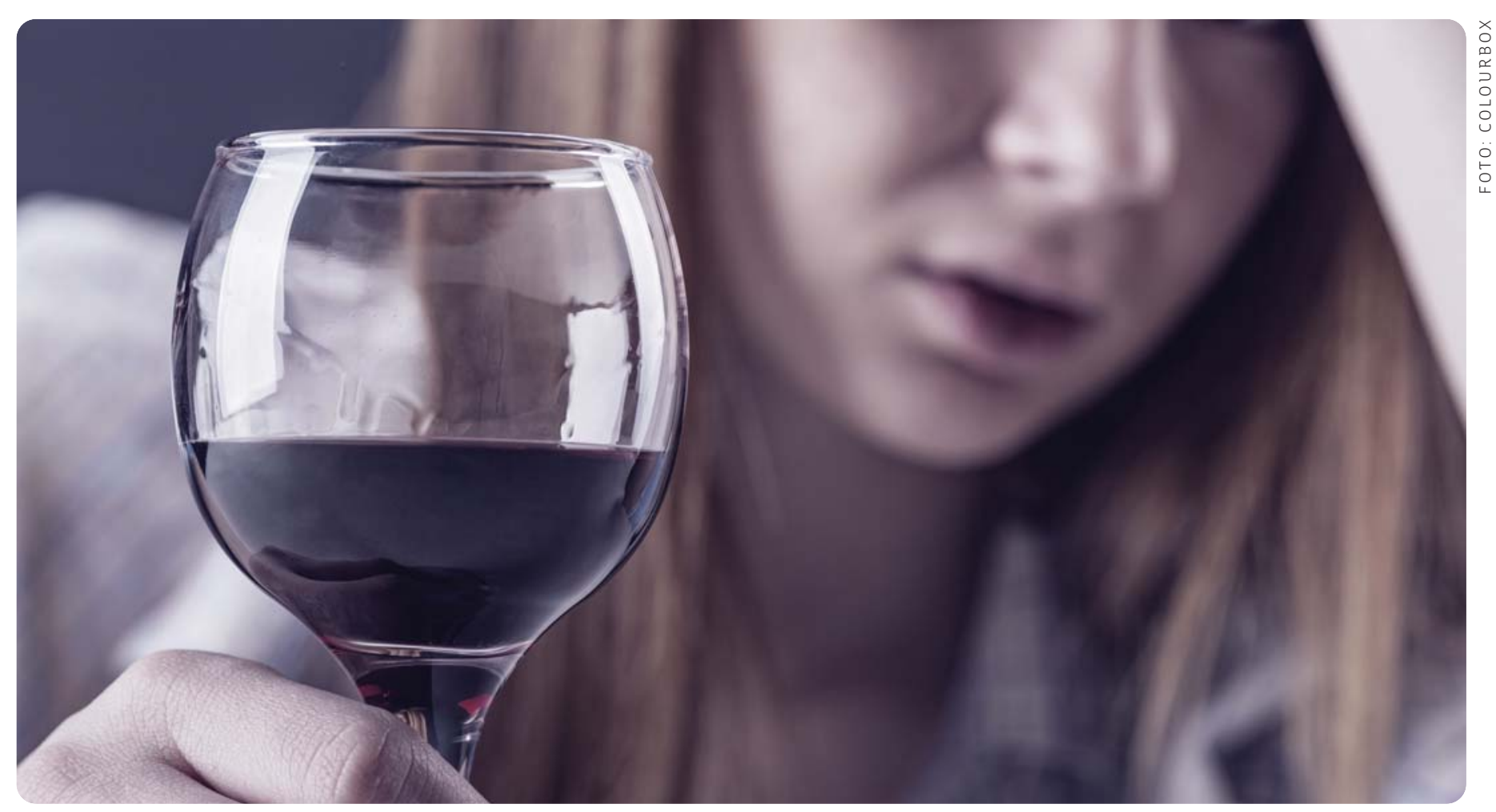

Men som Skog framhåller i sin genomgång (Skog 1991) av Durkheims självmordsteori är storkonsumtion starkt påverkat av samhälleliga faktorer och varierar enormt över såväl tid som rum. Det är inte heller särskilt långsökt att integrera konsekvenserna av storkonsumtion i Durkheims självmordsteori. En central tes i denna teori är att självmordsrisken är omvänt relaterad till graden av integration. Det finns åtskilliga studier som visar att alkoholmissbrukare har en bristande social integration. Delvis beror detta säkert på en selektionseffekt, på så sätt att de som utvecklar ett alkoholmissbruk har en bristande integration redan innan dryckeskarriären påbörjas. Det finns dock undersökningar som indikerar att missbruket i sig försämrar sociala relationer, till exempel att familjeband och vänskapsrelationer försämras i takt med att missbruket utvecklas.

Berusning är en annan tänkbar mekanism bakom kopplingen mellan alkohol och självmord. Tillståndet av berusning kan minska den impulskontroll som håller tillbaka en suicidal benägenhet (Hufford 2001). För att anknyta till Durkheims självmordsteori kan berusningen betraktas som en form av anomi, alltså ett tillstånd där normala kontrollmekanismer försvagas eller sätts ur spel (Skog 1991). Vidare ökar högkonsumtion risken för depression (Boden and Fergusson 2011), som är en väletablerad riskfaktor för självmord.

\section{Att analysera sambandet} mellan alkohol och självmord på befolkningsnivå

Ett centralt fynd inom alkoholepidemiologi är att en ökning i ett lands totalkonsumtion är kopplad till en ökning i andelen storkonsumenter och antalet berusningstillfällen (Skog 1985). Mot bakgrund av de ovan diskuterade mekanismerna mellan alkohol och självmord bör vi sålunda förvänta oss ett samband på befolkningsnivå mellan totalkonsumtion och antalet självmord. Lämpligaste metoden för att testa denna hypotes är att analysera tids- serier med årsdata på alkoholkonsumtion/ capita (vanligen mätt med försäljning) och självmord, vanligen uttryckt som en rat, det vill säga antalet självmord per 100000 invånare (ofta med uppdelning på män och kvinnor och ibland olika åldersgrupper). Analyser av tidsseriedata rymmer flera komplikationer, och om dessa inte beaktas är det lätt att dra felaktiga slutsatser. Den kanske viktigaste komplikationen är gemensamma tidstrender; om alkoholkonsumtionen och självmordstalet båda har en ökande trend så betyder inte det nödvändigtvis att de är kausalt relaterade till varandra. Ett sätt att minska risken för spuriösa samband är att eliminera trenderna genom att differentiera data. Detta innebär att man i stället för att analysera trender undersöker i vilken grad årliga förändringar i konsumtion är kopplade till årliga förändringar i suicid. Ytterligare en komplikation är att man kan förvänta sig en struktur i restledet (som innehåller andra orsaksfaktorer) vilket gör att den vanliga formen för regressionsanalys inte kan tillämpas. 
Flertalet studier publicerade under de senaste två decennierna är baserade på den teknik för tidsserieanalys som utvecklats av Box \&t Jenkins (Box, Jenkins et al. 2008) vilken brukar benämnas ARIMA (autoregressive integrated moving average model). Denna teknik tar hänsyn till de komplikationer som nämnts här och ger därmed mer tillförlitliga fynd än enkla trendanalyser (se (Norström and Skog 2001) för en utförligare beskrivning). Även om analyser av samband på aggregerad nivå är förenade med flera metodologiska komplikationer, bör man samtidigt framhålla en stor fördel, nämligen att risken för selektionsbias elimineras. $0 \mathrm{~m}$ man på basis av individnivådata finner att alkoholmissbrukare har en förhöjd självmordsrisk finns det alltid en risk att detta beror på någon gemensam bakomliggande faktor, exempelvis depression (se figur 1A). Men denna källa till bias försvinner på aggregerad nivå om vi gör det rimliga antagandet att variationer i prevalensen depression i samhället inte påverkar totalkonsumtionen av alkohol (figur 1B).

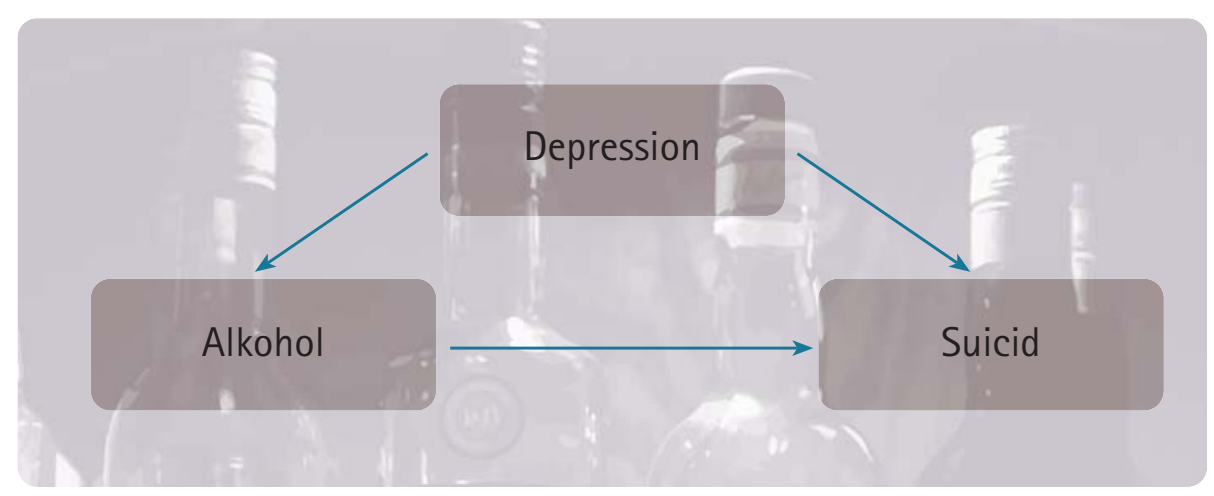

Figur 1B

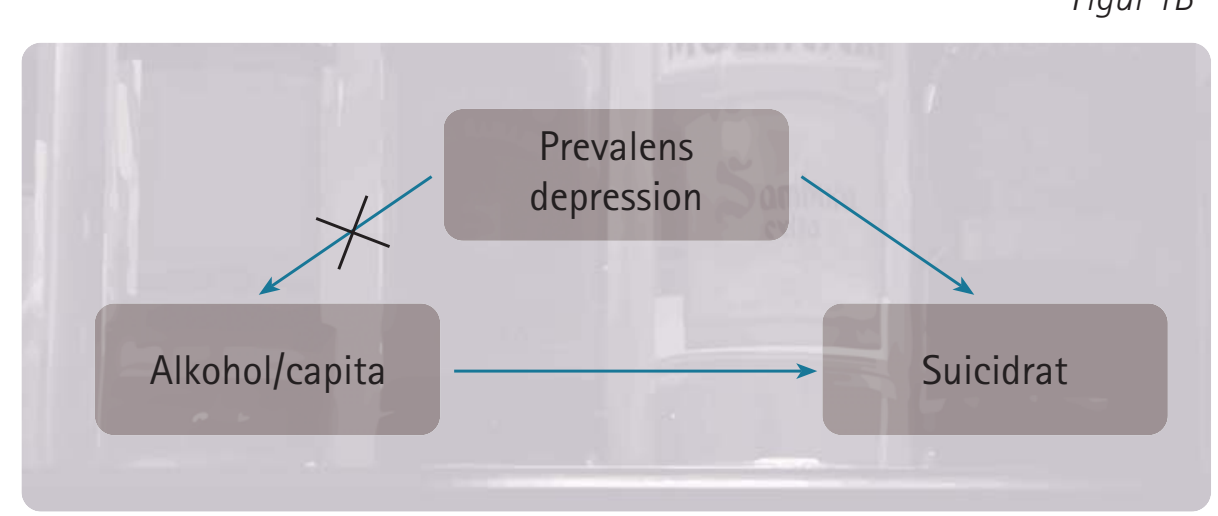

Visserligen är det möjligt att inkludera kontrollvariabler i analyser av individnivådata, men det finns gränser för detta; det är till exempel nära nog omöjligt att kontrollera för genetiskt betingade konfounders åtminstone med vanliga undersökningsdesigner.

Studier på aggregerad nivå kan även göras på basis av tvärsnittsdata, till exempel genom analyserer av variationen i alkoholkonsumtion och suicidrater mellan länder. En begränsning med denna ansats är att suicidratens täckningsgrad (i vilken grad den speglar det faktiska antalet självmord) sannolikt varierar mellan länder på grund av skillnader i kulturella faktorer i synen på självmord. Om denna variation i täckningsgrad samvarierar med totalkonsumtionen av alkohol finns det en uppenbar risk för att dra felaktiga slutsatser. I tidsserieanalys utnyttjas endast variation inom landet, vilket minimerar inflytandet av de kulturella faktorer som påverkar täckningsgraden.

Figur $1 \mathrm{~A}$

\section{Litteratursökning}

Genomgången av studier baseras på sökningar i MedLine och Social Sciences

Citation Index med söksträngen "alcohol AND suicide AND time series". Sökningen begränsades till artiklar publicerade efter 1989. Efter uteslutning av artiklar som låg utanför ämnesområdet, och efter komplettering med manuella sökningar i referenslistor återstod 42 studier.

\section{Resultat}

De flesta (34) av de 42 studierna presentarar genusspecifika estimat av sambandet mellan totalkonsumtionen av alkohol och självmord. Som framgår av översikten i tabell 1 var det ingen studie som rapporterade ett signifikant negativt samband mellan totalkonsumtionen och självmord. Cirka hälften (53 \%) av sambanden för män var signifikant positiva, för kvinnor var denna andel markant lägre, cirka en tredjedel (37\%).

Ett par studier med fokus på Ryssland använde alkoholrelaterad dödlighet som proxy för konsumtion. (Pridemore and Chamlin 2006) rapporterar ett signifikant positivt samband mellan denna proxy och suicid för både män och kvinnor för perioden 1956-2002. (Stickley, Jukkala et al. 2011) fann att detta samband hade ungefär samma styrka i Ryssland under perioden 1956-2005 som under perioden 1870-1894.

\section{Naturliga experiment}

Några studier bygger på så kallade naturliga experiment där man studerar effekten på självmord av en markant förändring i totalkonsumtionen som åstadkommits genom någon form av statlig intervention, till exempel en höjning av alkoholskatten. Den stora fördelen med att basera analysen på ett naturligt experiment är att man vet varför den förklarande variabeln förändrades, vilket vanligen gör det möjligt att utesluta att en gemensam bakomliggande faktor ligger bakom en samtidig förändring i utfallet och den förklarande variabeln. 
Tabell 1. Studier av sambandet mellan alkohol och självmord på befolkningsnivå baserade på tidsseriedata publicerade 1990-2013. Ändring i självmordstalet (\%) vid 1 liters ökning i alkoholkonsumtionen/capita.

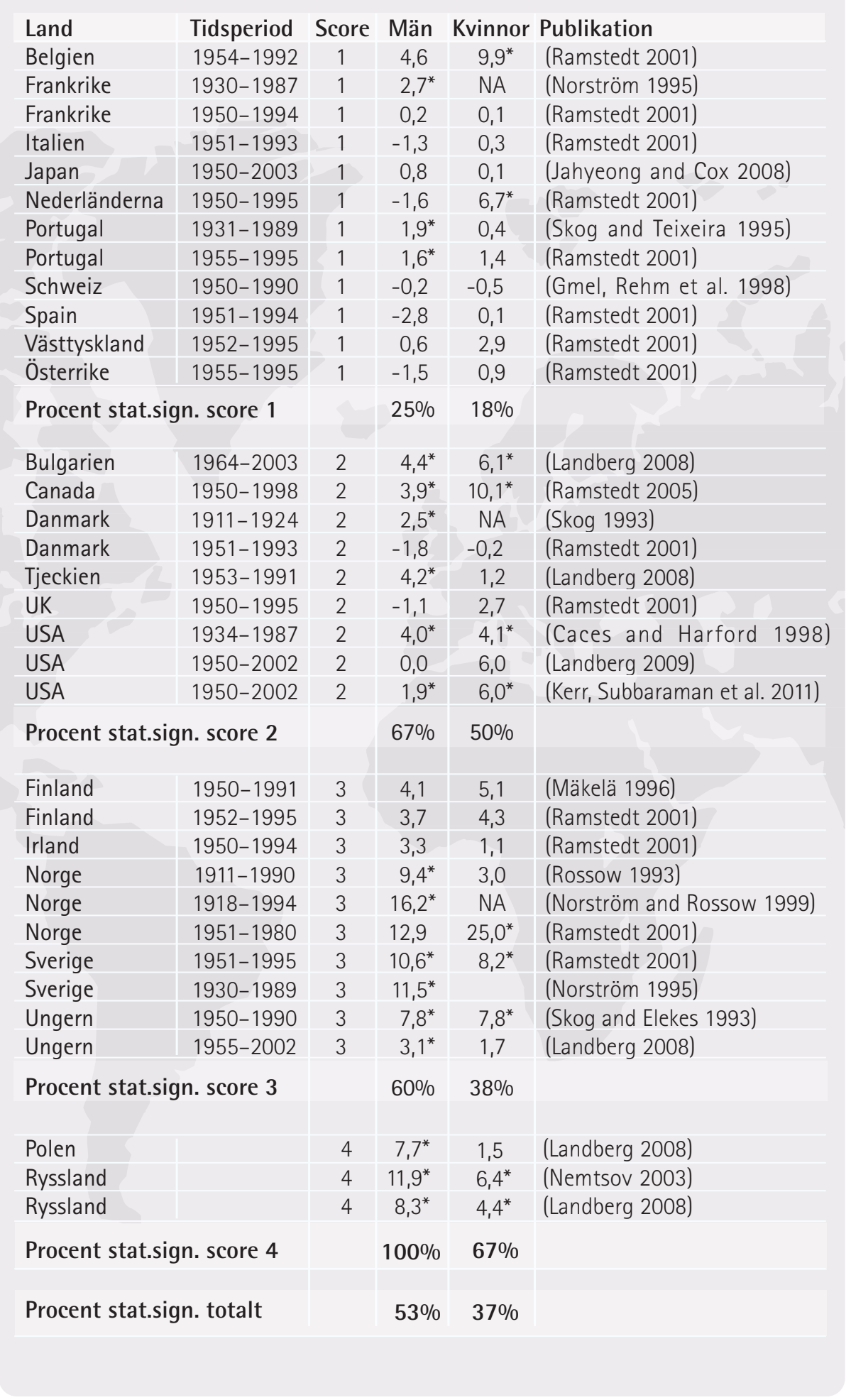

*Statistiskt signifikant på 5\%-nivån

Score: Pattern score. 1 indikerar det minst skadliga, och 4 det mest skadliga dryckesmönstret.
Ett av dessa naturliga experiment ägde rum i Danmark för nära hundra år sedan. På grund av bristen på livsmedel under första världskriget införde den danska regeringen under åren 1917-1918 en rad restriktioner på alkoholområdet, däribland en skattehöjning som mer än tiobubblade priset på starksprit. Detta ledde till en minskning av totalkonsumtionen från cirka 10 liter 1916 till drygt 2 liter 1918. Även om konsumtionen senare kom att öka något kvarstod den på en låg nivå (3-4 liter) under hela mellankrigstiden (Thorsen 1990). Den danska självmordsstatistiken innehöll vid denna tidsperiod uppgifter om självmordsoffrets dryckesstatus (missbrukare/icke missbrukare) som grundades på rättsläkarens rapport. I sin analys finner Skog (Skog 1993) att den dramatiska konsumtionsminskningen följdes av en halvering i missbrukarsjälvmorden medan antalet övriga självmord inte förändrades. Detta utfall ger ett extra starkt stöd för hypotesen om en koppling mellan alkohol och suicid på befolkningsnivå: eftersom minskningen $i$ totalkonsumtionen åtföljdes av ett minskat antal självmord endast bland missbrukare, verkar det inte troligt att minskningen i det totala antalet självmord skulle bero på de historiska händelser som låg bakom konsumtionsminskningen. Det mest välkända naturliga experimentet på alkoholområdet torde vara Gorbachev's anti-alkoholkampanj. År 1985 genomfördes en markant skärpning i den sovjetiska alkoholpolitiken som innebar minskad produktion av alkoholhaltiga drycker, höjda alkoholpriser och minskad tillgänglighet genom en reduktion av antalet försäljningsställen och minskade öppettider (Reitan 2000). Även om kampanjen var relativt kortvarig och i praktiken upphörde 1989, ledde den till en markant, om än temporär, minskning av totalkonsumtionen. Enligt Nemstovs skattningar minskade konsumtionen i Ryssland från cirka 14,6 liter i 1984 till 10,8 liter i 1986 (Nemtsov 2000). 
I en serie arbeten har Wasserman och medarbetare studerat hur detta naturliga experiment inverkat på den ryska dödligheten i suicid (Wasserman, Värnik et al. 1994; Wasserman och Värnik 1998; Wasserman, Värnik et al. 1998). Resultaten tyder på markanta effekter; sålunda beräknas självmorden bland män ha minskat med cirka $42 \%$, och bland kvinnor med ungefär $20 \%$.

\section{Kulturella variationer}

Ett par studier syftar till att undersöka om sambandet mellan alkohol och självmord varierar mellan olika dryckeskulturer. Även om det finns flera skäl att förvänta sig en sådan variation (Norström 1995; Ramstedt 2001) är det främst skillnader i dryckesmönstren som bör ha betydelse. En komparativ survey av alkoholkonsumtion i sex europeiska länder (Leifman 2002) gav stöd för den stereotypa uppfattningen att berusningsdrickande är vanligare $\mathrm{i}$ torra kulturer (representerade av Finland och Sverige) än i våta (Frankrike och Italien), där drickandet i högre grad utgörs av måltidsdrickande fördelat på de flesta av veckans dagar. Detta innebär att en given ökning i totalkonsumtionen bör ge ett starkare utslag på berusningsdrickande (och därmed självmordstalet) i en torr jämfört med en våt dryckeskultur. Två studier finner stöd för denna hypotes; sålunda observerade (Norström 1995) ett starkare samband mellan totalkonsumtionen och självmord i Sverige än i Frankrike. I en studie baserad på 14 europeiska länder rapporterar (Ramstedt 2001) starka och statistiskt signifikanta samband för de nordiska länderna, men svaga och oftast icke-signifikanta samband för Mellanoch Sydeuropa. För att få ett ytterligare och mer globalt test av den aktuella hypotesen har studierna i tabell 1 grupperats utifrån den skattning av dryckesmönster som presenteras i (Rehm, Room et al. 2004). Skattningen utgörs av en "pattern score" mellan 1 och 4, där 1 indikerar det minst skadliga och 4 det mest skadliga dryckesmönstret. Även här ser vi ett mönster som är förenligt med hypotesen; ländergrupperna med pattern score 3 och 4 har en större andel signifikanta samband (och starkare samband) än ländergrupperna med pattern score 1 och 2 .

\section{Dryckesspecifika effekter}

Några studier pekar på att vissa alkoholhaltiga drycker skulle ha starkare koppling till suicid än andra. Det gäller främst sprit (Japan (Norström, Stickley et al. 2012), Norge (Norström och Rossow 1999), Ryssland (Razvodovsky 2010), Sverige (Norström och Rossow 1999) och USA (Gruenewald, Ponicki et al. 1995)), men även öl (Norge (Norström och Rossow 1999)). Den mest närliggande tolkningen är att sprit (och i viss mån öl) är den alkoholhaltiga dryck som föredras av storkonsumenter (vilka utgör en riskgrupp för suicid).

\section{Åldersspecifika effekter}

Flera studier pekar på att alkoholfaktorn skulle ha större betydelse för självmordsbeteende bland yngre och medelålders än bland äldre (Brady 2006), vilket möjligen kan bero på att berusningsdrickande är vanligare bland yngre än bland äldre. Resultat baserade på data för USA (Caces och Harford 1998) och Finland (Mäkelä 1996) ligger i linje med detta, det vill säga ett signifikant samband mellan totalkonsumtionen och suicid framkom bara när de äldre åldersgrupperna exkluderas från analysen.

\section{Diskussion}

Denna artikel har gett en översikt över de studier som har analyserat kopplingen mellan alkohol och självmord på befolkningsnivå. Vad är då det samlade bidraget av denna litteratur? Den teoriutveckling som har gjorts i detta sammanhang må vara blygsam men måste ändå sägas vara en breddning av Durkheims självmordsteori till att inkludera ytterligare en faktor av betydelse för de marginaliserings- och desintegrationsprocesser $i$ samhället som är kopplade till ökad suicidrisk. Även alkoholepidemiologiskt har denna forskning inneburit en breddning. De tidiga arbetena på befolkningsnivå dokumenterade ett samband mellan totalkonsumtion och somatiska skador (främst i form av levercirros). Fokuset på självmord vidgar perspektivet genom att inkludera även drickandets sociala skador. Samtidigt modifierar resultaten betydelsen av en av hörnstenarna i totalkonsumtionsmodellen; även om totalkonsumtionen framstår som en viktig faktor bakom självmordsutveckligen i många länder är det tydligt att dess inverkan modifieras av landets dryckeskultur och dryckesmönster. I länder med det mest skadliga dryckesmönstret (till exempel de nordiska länderna) ligger effektstorleken på cirka $10 \%$ per liter för män (en konsumtionsökning på 1 liter/ capita leder till en ökning i självmordstalet på cirka $10 \%$ ). Motsvarande siffra för länder med det minst skadliga dryckesmönstret (och där sambandet är signifikant) är $2 \%-3 \%$. Ett liknande mönster har noterats för sambandet mellan totalkonsumtionen och olika former av våld, såsom misshandel och mord (Lenke 1990; Rossow 2001). Det finns också en metodologisk lärdom att dra av genomgången. Även om det finns teoretiska skäl att förvänta sig ett samband mellan alkohol och suicid på befolkningsnivå kan detta samband av olika orsaker vara svårt att upptäcka. Sålunda kan sambandet vara svagt, som i våta dryckeskulturer, vilket skapar ett ogynnsamt förhållande mellan signal och brus. En möjlig lösning i denna situation är att välja en period med en kraftig variation i totalkonsumtionen, vilket ger en ökad power att upptäcka ett eventuellet samband. Ett exempel är Danmark, där Ramstedt inte fann något signifikant samband på basis av data för perioden 1951-1993. Skog använde i stället perioden 1911-1924. 
Det ringa antalet observationer uppvägs av det faktum att konsumtionen föll med cirka 77 \% mellan 1916 och 1918, vilket gav tillräcklig power för att få ett signifikant estimat av den förväntat svaga effekten (2,5\% per liter). Ett liknande exempel är Frankrike, där Ramstedts anaIys (Ramstedt 2001) för perioden 19501994 inte resulterade i något signifikant estimat, vilket dock Norströms analys (Norström 1995) gjorde, sannolikt för att den var baserad på en period (19301987) med kraftigare fluktuationer $i$ totalkonsumtionen.

Översikten visar att de flesta studier av sambandet mellan alkohol och självmord på befolkningsnivå gjorts på data från utvecklade västländer. Framtida studier bör vidga perspektivet till analyser av data från länder som representerar andra kulturer och utvecklingsnivåer.

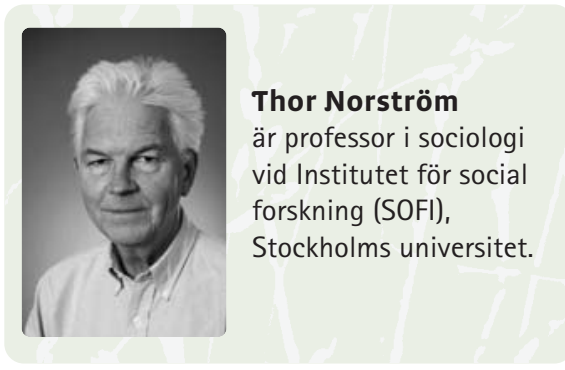

\section{Referenser}

Boden, J.M. and D.M. Fergusson (2011). Alcohol and depression. Addiction 106: 906-914.

Box, G.E.P., G. M. Jenkins, et al. (2008). Time Series Analysis: forecasting and control. New York, Wiley Brady, J. (2006). The association between alcohol misuse and suicidal behaviour. Alcohol and Alcoholism 41: 473-478.

Caces, F. \& Harford, T. (1998). Time series analysis of alcohol consumption and suicide mortality in the United States, 1934-1987. Journal of Studies on Alcohol 59: 455-461.

Durkheim, E. (1952 [1897]). Suicide: A study in sociology. London, England, Routledge \&t Kegan Paul.

Gmel, G., Rehm, J. et al. (1998). Alcohol and suicide in Switzerland - an aggregate-level analysis. Drug and Alcohol Review 17: 27-37.

Gruenewald, P.J., Ponicki, W.R. et al. (1995). Suicide rates and alcohol consumption in the United States, 1970-89. Addiction 90: 1063-1075.
Hufford, M.R. (2001). Alcohol and suicidal behavior. Clinical Psychology Review 21: 797-811. Jahyeong, K. \&t Cox, W.M. (2008). An economic interpretation of suicide cycles in Japan. Contemporary Economic Policy 26: 162-174.

Kerr, W.C., Subbaraman, M., et al. (2011). Per capita alcohol consumption and suicide mortality in a panel of US states from 1950 to 2002. Drug and Alcohol Review 30: 473-480.

Landberg, J. (2008). Alcohol and suicide in eastern Europe. Drug and Alcohol Review 27: 361-373.

Landberg, J. (2009). Per capita alcohol consumption and suicide rates in the U.S., 19502002. Suicide and Life-Threatening Behavior 39: 452-460.

Leifman, H. (2002). The six-country survey of the European comparative alcohol study: comparing patterns and assessing validity. Contemporary Drug Problems 29: 477-500.

Lenke, L. (1990). Alcohol and Criminal Violence: Time Series Analysis in a Comparative Perspective. Stockholm, Almqvist and Wiksell International.

Mäkelä, P. (1996). Alcohol consumption and suicide mortality by age among Finnish men, 1950-1991. Addiction 91: 101-112.

Nemtsov, A. (2003). Suicides and alcohol consumption in Russia, 1965-1999. Drug and Alcohol Dependence 71: 161-168.

Nemtsov, A. V. (2000). Estimates of total alcohol consumption in Russia, 1980-1994. Drug and Alcohol Dependence 58: 133-142.

Norström, T. (1995). Alcohol and suicide: a comparative analysis of France and Sweden. Addiction 90: 1463-1469.

Norström, T. (1995). The impact of alcohol, divorce, and unemployment on suicide: a multilevel analysis. Social Forces 74: 293-314.

Norström, T. \& I. Rossow (1999). Beverage specific effects on suicide. Nordic Studies on Alcohol and Drugs 16: 109-118.

Norström, T. \&t 0.-J. Skog (2001). Alcohol and mortality: methodological and analytical issues in aggregate analyses. Addiction 96: 5-17.

Norström, T., Stickley, A., et al. (2012). The importance of alcoholic beverage type for suicide in Japan: A time-series analysis, 1963-2007. Drug \&t Alcohol Review 31: 251-256.

Pridemore, W.A. \& Chamlin, M.B. (2006). A timeseries analysis of the impact of heavy drinking on homicide and suicide mortality in Russia, 1956-2002. Addiction 101: 1719-1729.

Ramstedt, M. (2001). Alcohol and suicide in 14 European countries. Addiction 96: 59-75.

Ramstedt, M. (2005). Alcohol and suicide at the population level - the Canadian experience. Drug and Alcohol Review 24: 203-208.

Razvodovsky, Y. E. (2010). Beverage-specific alcohol sales and violent mortality in Russia. Adicciones 22: $311-315$.
Rehm, J., Room, R., et al. (2004). Alcohol use. Comparative quantification of health risks. Global and regional burden of disease attributable to selected major risk factors (vol 1). M. Ezzati, A. D. Lopez, A. Rodgers and C. J. L. Murray. Geneva: 959-1109.

Reitan, T. (2000). Does alcohol matter? Public health in Russia and the Baltic countries before, during, and after the transition. Contemporay Drug Problems 27: 511-560.

Rossow, I. (1993). Suicide, alcohol, and divorce; aspects of gender and family integration. Addiction 88: 1659-1665.

Rossow, I. (2001). Alcohol and homicide: A crosscultural comparison of the relationship in 14 European countries. Addiction 96: 77-92.

Skog, 0.-J. (1985). The collectivity of drinking cultures: a theory of the distribution of alcohol consumption. British Journal of Addiction 80: 83-99. Skog, 0.-J. (1991). Alcohol and suicide - Durkheim revisited. Acta Sociologica 34: 193-206.

Skog, 0.-J. (1993). Alcohol and suicide in Denmark 1911-24 - experiences from a 'natural experiment'. Addiction 88: 1189-1193.

Skog, 0.-J. and Elekes, Z. (1993). Alcohol and the 1950-90 Hungarian suicide trend - Is there a causal connection? Acta Sociologica (Taylor \& Francis Ltd) 36: 33-46.

Skog, 0.-J. and Teixeira, Z. (1995). Alcohol and suicide - the Portuguese experience. Addiction 90: 1053-1061.

Stack, S. (1982). Suicide: A decade review of the sociological literature. Deviant Behavior 4: 41-66. Stack, S. (2000). Suicide: A 15-Year review of the sociological literature part I: Cultural and economic factors. Suicide and Life-Threatening Behavior 30: 145-162.

Stickley, A., Jukkala, T., et al. (2011). Alcohol and suicide in Russia, 1870-1894 and 1956-2005: Evidence for the continuation of a harmful drinking culture across time? Journal of Studies on Alcohol and Drugs 72: 341-347.

Thorsen, T. (1990). Hundrede års alkoholmisbrug, alkoholforbrug og alkoholproblemer i Danmark. København, Alkohol- og narkotikarådet.

Wasserman, D. \&t Värnik, A. (1998). Suicide-preventive effects of perestroika in the former USSR: the role of alcohol restriction. Acta Psychiatrica Scandinavica 98: 1-4.

Wasserman, D., Värnik, A., et al. (1994). Male suicides and alcohol consumption in the former USSR. Acta Psychiatrica Scandinavica 89: 306-313.

Wasserman, D., A. Värnik, et al. (1998). Female suicides and alcohol consumption during perestroika in the former USSR. Acta Psychiatrica Scandinavica 98: 26-33. 